\title{
Effects of addition of Magnesium sulphate to heavy Bupivacaine for spinal anaesthesia in vaginal hysterectomy
}

Tabdar S', Shrestha U2 ${ }^{2}$ Kadariya ER ${ }^{3}$

'Sushila Tabdar, Assistant Professor, '2Uzma Shrestha, Lecturer, Department of Anaesthesiology and Intensive care, Kathmandu medical College, Kathmandu, Nepal

${ }^{3}$ Ekraj Kadariya, Lecturer, Trichandra Multiple Campus, Tribhuvan University.

\section{Abstract}

Background: Adequate pain management is essential for every patient to recover and return to their normal activity quickly. Central sensitization is one of the mechanism which increases excitability of spinal neurons and results persistent pain postoperatively.

Objectives: The aim of the study was to investigate the effects of addition of $100 \mathrm{mg} 50 \%$ Magnesium Sulphate intrathecally to $0.5 \%$ heavy Bupivacaine on sensory onset up to T4 level, complete motor block, post-operative analgesia and complications in patients planned for vaginal hysterectomy under spinal anesthesia.

Methods: The design of the study was prospective randomized and double blind. With the Institutional improvements and informed consent in Kathmandu Medical College from January 2011 till December 2012, 60 American society of Anesthesiologist class (I, II) patients of age between (40 to 70 ) years, weight between ( 45 to 70 ) $\mathrm{kg}$ and height between (4.8 to 5.2) feet undergoing routine vaginal hysterectomy not exceeding one and half hour in spinal anaesthesia were included in the study. The exclusion criteria were patients not following above criteria, having coagulopathy, renal function derangements, uncontrolled hypertension or severe hypotension and having dysarrhythmias. Total patients were randomized into two groups of thirty each. Group A was allocated to receive four $\mathrm{ml} 0.5 \%$ Bupivacaine $+0.25 \mathrm{ml}$ normal saline and group B was allocated to receive four $\mathrm{ml} 0.5 \%$ Bupivacaine $+100 \mathrm{mg}$ of $50 \%$ Magnesium Sulphate. The anaesthesiologist who was double blind to the drug preparation performed spinal anaesthesia with either of the drug for the whole study.The recorded parameters were time of onset of sensory block upto T4 level, onset of complete motor block, total duration of analgesia and complications in both the groups. Data analysis was done by Computer software polystat XLS using Student's " $t$ " test. P value $<0.05$ was considered statistically significant.

Result: The addition of $100 \mathrm{mg}$ of $50 \%$ Magnesium sulphate to $0.5 \%$ Bupivacaine intrathecally resulted early onset of sensory block upto T4 level in (Mean \pm SD) $(3.79 \pm 0.25) \mathrm{min}$ Vs $(9.61 \pm 0.75) \mathrm{min}$ with sole $0.5 \%$ Bupivacaine where $p$ value was $<0.05$. Similarly onset of complete motor block with $0.5 \%$ Bupivacaine plus Magnesium Sulphate was $(1.9 \pm 0.23)$ min verses (10.4 \pm 0.63 ) min with $0.5 \%$ Bupivacaine only. Here again p value was $<0.05$. Duration of analgesia with 0.5 $\%$ Bupivacaine plus Magnesium Sulphate was $(176.8 \pm 19.85)$ min than that of $0.5 \%$ Bupivacaine $(105 \pm 26.82)$ min with $P$ value $<0.05$.

Conclusion: The study concluded that onset as well as analgesic effect of $0.5 \%$ Bupivacaine was potentiated by intrathecal Magnesium Sulphate without major side effects.

Key words: Bupivacaine, Magnesium Sulphate, Spinal anaesthesia.

\section{INTRODUCTION}

A ddition of various adjuvants to $0.5 \%$ hyperbaric Bupivacaine for spinal anaesthesia is not new to the

\section{Address for correspondence}

Dr. Sushila Tabdar

Assistant Professor, Department of Anaesthesiology and Intensive care

Kathmandu Medical College Teaching Hospital,

Kathmandu, Nepal

E-mail: sutabdar@yahoo.co.in
Anaesthesiologists of this era. Different kinds of drugs like Opioids, Clonidine, Ketamine, Neostigmine and many more are added with the hope of having some additional beneficial effects like fast sensory and motor onset, less alteration in haemodynamics, minimal side effects and prolongation of analgesia.

Till now we have seen that sole $0.5 \%$ hyperbaric Bupivacaine has been able to result only short period of analgesia, causing hemodynamic alterations with 
moderate to high concentrations and delayed sensory and motor onset in various abdominal surgeries. In a study by Bharti N, Modan R, Kaul HL et al forty adult patients undergoing lower abdominal surgery with $3 \mathrm{ml}$ $0.5 \%$ Bupivacaine alone or $3 \mathrm{ml}$ 0.5\% Bupivacaine plus $1 \mathrm{mg}$ Midazolam showed that duration of sensory block with $3 \mathrm{ml}$ 0.5\% Bupivacaine plus $1 \mathrm{mg}$ Midazolam was prolonged ( 218 minutes Vs 165 minutes, $\mathrm{p}<0.001$ ). Similar effective analgesia duration was observed with $3 \mathrm{ml} 0.5 \%$ Bupivacaine plus 1mg Midazolam (199 minutes Vs 103 minutes, $\mathrm{P}<0.001)^{1}$. Though in recent year intrathecal opioids as adjuvant to $0.5 \%$ hyperbaric Bupivacaine are commonly used but due to some important side effects like respiratory depression, nausea, vomiting, pruritus has limited their use very frequently ${ }^{2}$. As an alternative to opioids, Magnesium sulphate $\left(\mathrm{MgSO}_{4}\right)$ has been successfully used as an adjuvant in spinal Anaesthesia along with $0.5 \%$ Bupivacaine in many studies nowadays. One of the important mechanisms for the persistence of post-operative pain is considered to be due to central sensitization which increases the excitability of spinal neurons. This sensitization has been found dependent on N-Methyl D-Aspartate (NMDA) receptors activating excitatory Aspartates and Glutamates on dorsal horn ${ }^{3,4}$. Because Magnesium is a noncompetitive antagonist of NMDA receptor it has the potential to prevent central sensitization from peripheral nociceptive stimulation ${ }^{5,6}$. There are enough evidence based studies which has shown that intrathecal magnesium is able to potentiate the analgesic effect both in humans and animals by the proposed mechanism of antagonism of NMDA receptors ${ }^{7}$.

The addition of intrathecal Magnesium Sulphate to 10mg Bupivacaine plus $25 \mathrm{mcg}$ Fentanyl prolonged spinal anaesthesia in patients undergoing lower extremity surgery ${ }^{8}$. In Buvendran et al study $50 \mathrm{mg}$ intrathecal Magnesium Sulphate potentiated Fentanyl analgesia without producing motor block in patient during labor 9 . In another study by Arcioni et al patient received intrathecal Magnesium Sulphate (94.5 mg ) epidural Magnesium Sulphate (100 mg / hr), intrathecal and epidural Magnesium Sulphate combined or spinal alone. Post-operative morphine consumption at 36 hour after surgery was $38 \%$ lower in patients receiving SpinalAnaesthesia plus epidural Magnesium Sulphate, $49 \%$ lower in those receiving Spinal Anaesthesia plus intrathecal Magnesium Sulphate and $69 \%$ lower in both intrathecal and epidural Magnesium Sulphate group ${ }^{10}$.

Similarly Magnesium Sulphate has been found useful intrathecally in rats potentiating opioid analgesia ${ }^{11,12}$. In our study addition of $100 \mathrm{mg} 50 \%$ Magnesium Sulphate intrathecally to $0.5 \%$ heavy Bupivacaine was investigated for the onset of sensory block up to T4 level, complete motor block, duration of analgesia and complications for the patients undergoing vaginal hysterectomy with the assumption of hypothesis that the onset of sensory and motor block as well as duration of analgesia should be different with less complications.

\section{METHODS}

The design of the study was a prospective randomized and double blind. With the Institutional approvement and informed consent in Kathmandu Medical College from January 2011 to December 2012, 60 American society of Anesthesiologist class ( I, II) patients of age between (40 to 70 ) years, weight between (45 to 70) $\mathrm{kg}$ and height between (4.8 to 5.2) feet undergoing routine vaginal hysterectomy not exceeding one and half hours in spinal anaesthesia were included in the study. The exclusion criteria were patients not following above criteria, having coagulopathy renal function derangements, uncontrolled hypertension or severe hypotension and having dysarrhythmias. All of them were premedicated with Diazepam tablet one night before surgery. After arriving to the operation theatre, routine monitors were attached to every patient to monitor Pulse Rate (PR), Electro Cardiography (ECG), Arterial Oxygen Saturation $\left(\mathrm{SpO}_{2}\right)$ and Noninvasive Blood pressure (NIBP). All the patients were preloaded with Ringer's solution $500 \mathrm{ml}$ before subarachnoid block.

Total patients were parallelly grouped into two groups of thirty each to receive either $(0.5 \%$ Bupivacaine 20 $\mathrm{mg}+0.25 \mathrm{ml}$ Normal Saline) or (0.5\% Bupivacaine20 $\mathrm{mg}+100 \mathrm{mg}$ of $50 \%$ magnesium Sulphate) for randomized and double blind study. Subarachnoid block was then performed in a sitting position at L2-L3 inter space with the 27- Gauge Whitaker needle. The anaesthesiologist who was double blind to the study performed subarachnoid block and recorded vitals as well. The parameters recorded were time of onset of sensory block up to T4 level, complete motor block, haemodynamic parameters immediately after block till ninety minutes at the interval of five minutes duration of analgesia and complications during the whole operative period as well as 24 hours after operation in the postoperative ward. Adequate sensory block was assessed as no pain while pin prick uptoT4 level. Motor block was assessed using modified Bromage scale according to text book of Clinical anaesthesiology by $\mathrm{M}$ George and M Samir (0,no motor block;1,hip blocked;2, hip and knee blocked; 3, hip-knee-ankle blocked) ${ }^{13}$. Adequate motor block was regarded as complete motor block of 3 Bromage scale and recorded. Blood pressure 
recordings of $20 \%$ lower than the baseline value was taken as hypotension and treated accordingly, PR less than 45 was considered as bradycardia and treated with Atropine, finally $\mathrm{SpO}_{2}<90$ was taken as hypoxia and supplemented with Oxygen.

Total duration of analgesia was noted until the first analgesia was demanded for which injection Pethidine $1 \mathrm{mg} / \mathrm{kg}$ was used intramuscularly. Long term follow up was done till one month on phone call regarding any complications

Statistical analysis was done by Computer software polystat XLS using Student's " $\mathrm{t}$ " test. $\mathrm{P}$ value $<0.05$ was considered statistically significant.

\section{RESULT}

There were no significant differences between two groups in demographic profile as shown below in table 1.
Sensory onset up to T4 level with $0.5 \%$ Bupivacaine +Magnesium Sulphate was faster than 0.5\% Bupivacaine group where $p$ value was statistically significant i.e. $p=0.00$ by student's" $t^{\prime \prime}$ test which is shown in table

2. Complete motor block was also faster in $0.5 \%$ Bupivacaine +Magnesium Sulphate group than $0.5 \%$ Bupivacaine only, here $p$ value was 0.00 by student's " $\mathrm{t}$ " test as shown below in table 2. Duration of analgesia in group 0.5\% Bupivacaine + Magnesium Sulphate was longer than only $0.5 \%$ Bupivacaine where $p$ value was 0.00 by student's " $t$ " test.

Finally complications between two groups were compared and it was found that three patients in $0.5 \%$ Bupivacaine group had vomiting, seven patients had shivering, six patients had hypotension and four patients had bradycardia, post dural puncture headache was three in $0.5 \%$ Bupivacaine group and only one in $0.5 \%$ Bupivacaine Magnesium Sulphate group.

Table 1: Demographic profile in each group of the patients

\begin{tabular}{lccc} 
Variables & $\mathbf{0 . 5 \% B u p i v a c a i n e + M a g n e s i u m ~ S u l p h a t e [ M e a n ~} \pm$ SD] & $\mathbf{0 . 5 \%}$ Bupivacaine [Mean \pm SD] & P-Value \\
\hline Age(years) & $54.43 \pm 8.63$ & $56.37 \pm 8.52$ & 0.38 \\
Weight $(\mathrm{kg})$ & $58.77 \pm 6.97$ & $56.40 \pm 5.76$ & 0.16 \\
\hline Height(ft) & $4.98 \pm 0.14$ & $4.98 \pm 0.12$ & 0.92 \\
\hline
\end{tabular}

$\mathrm{p}$ value calculated by t test.

Table 2: Onset of sensory block, complete motor block, duration of analgesia between two groups.

\begin{tabular}{cccc}
\hline Measured Variables & $\begin{array}{c}\text { 5\% Bupivacaine+ Magnesium } \\
\text { Sulphate [Mean } \pm \text { SD] }\end{array}$ & $\begin{array}{c}\text { 0.5\% Bupivacaine } \\
\text { [Mean } \pm \text { SD] }\end{array}$ & P-Value \\
\hline Duration of Analgesia (min) & $176.10 \pm 19.85$ & $105.00 \pm 26.82$ & $<0.001$ \\
Onset of sensory block (min) & $3.70 \pm 0.25$ & $9.61 \pm 0.75$ & $<0.001$ \\
\hline complete Motor block (min) & $1.93 \pm 0.23$ & $10.39 \pm 0.63$ & $<0.001$ \\
\hline
\end{tabular}

$\mathrm{p}$ value calculated by t test.

Table 3: Complications between two groups (number of patients)

\begin{tabular}{lcc} 
Number of complications & $\mathbf{0 . 5 \%}$ Bupivacaine Magnesium Sulphate & $\mathbf{0 . 5 \%}$ Bupivacaine \\
Hypotension & 0 & 6 \\
Bradycardia & 0 & 4 \\
Vomiting & 0 & 3 \\
Shivering & 0 & 7 \\
Headache & 1 & 3 \\
\hline
\end{tabular}

Values are expressed in numbers. 


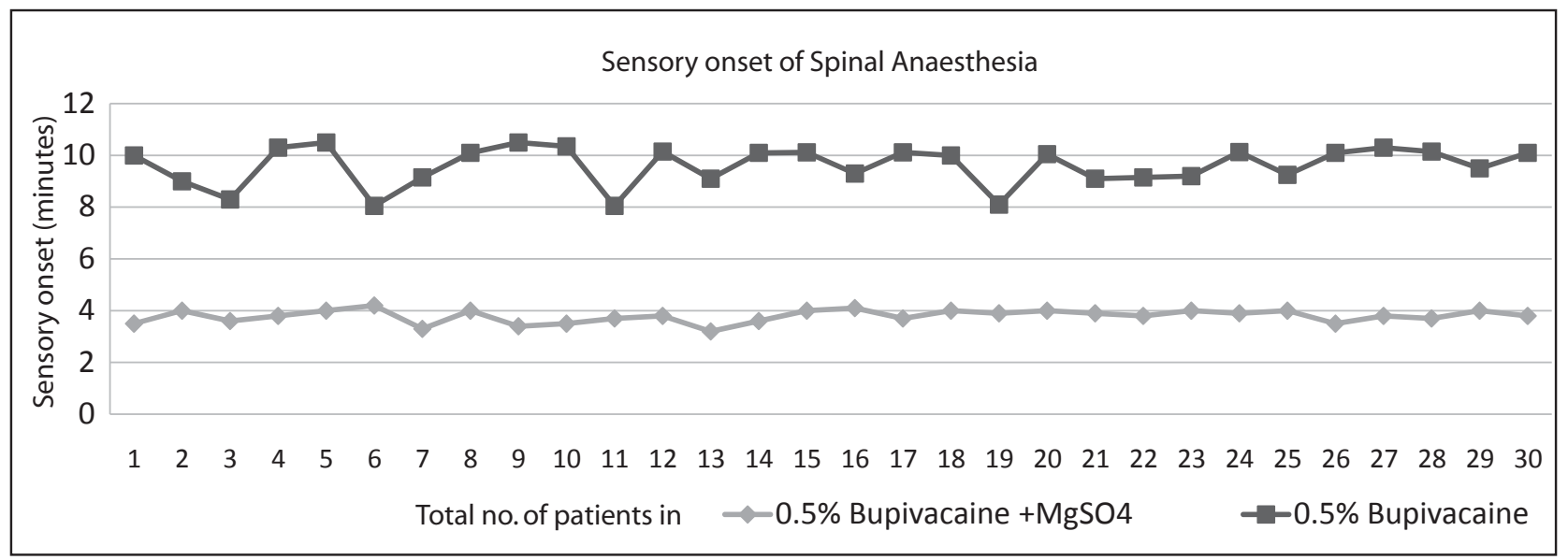

Figure 1: Sensory onset of spinal anaesthesia in two groups of patients.

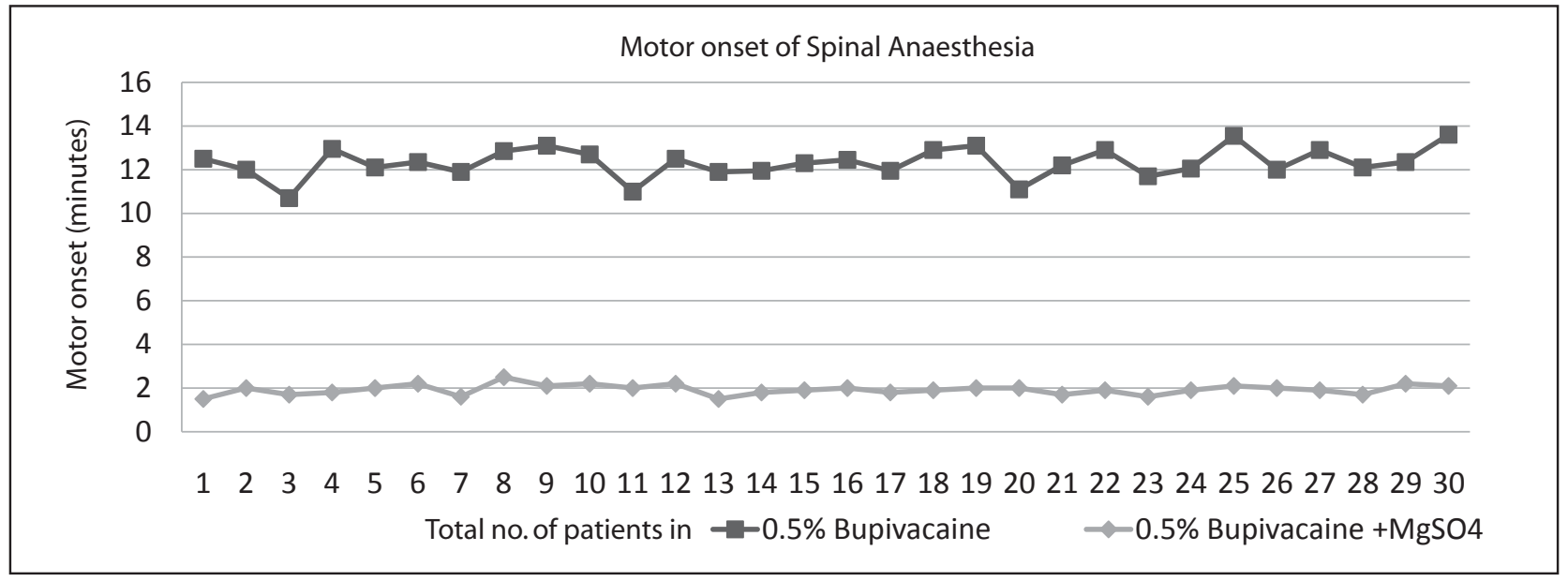

Figure 2: Motor onset of spinal anaesthesia in two groups of patients.

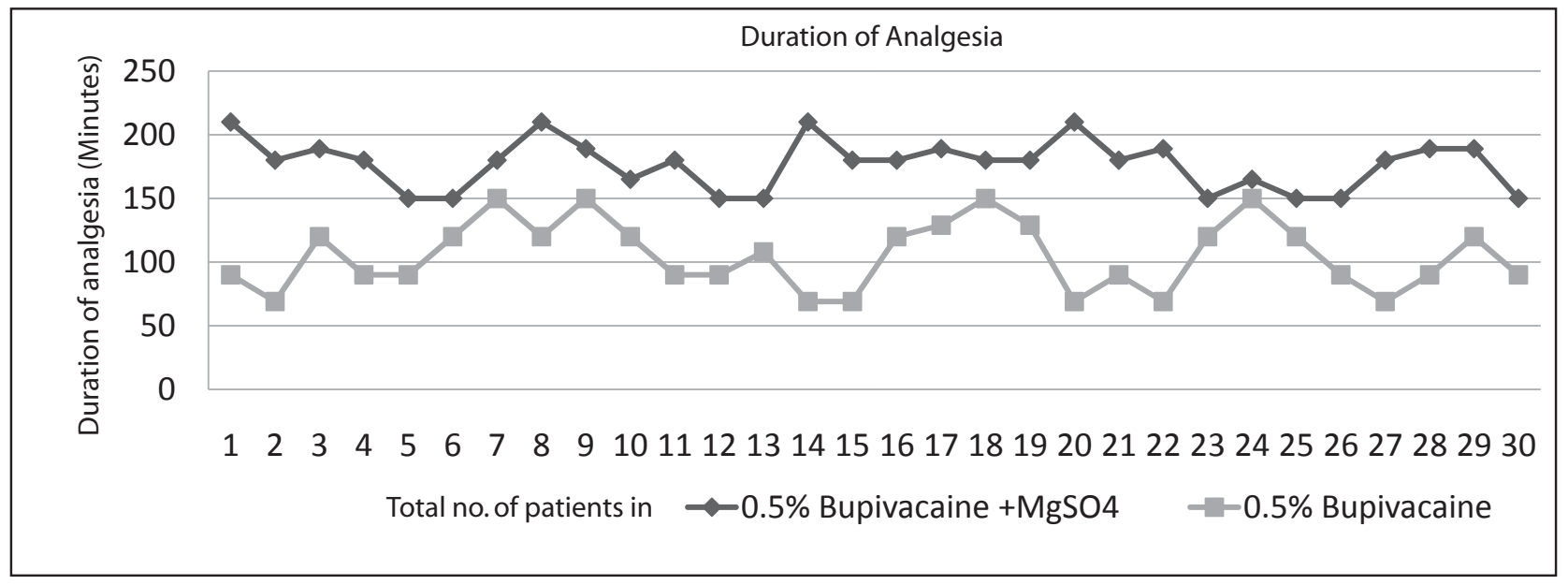

Figure 3: Duration of analgesia in two groups of patients. 


\section{DISCUSSION}

In our present study addition of Magnesium Sulphate to spinal anaesthesia with heavy Bupivacaine prolonged the duration of analgesia upto (176.8 \pm 19.85$)$ minutes Vs (105 \pm 26.82) minutes with sole $0.5 \%$ Bupivacaine. Similarly time taken for sensory block upto T4 level with $0.5 \%$ Bupivacaine + Magnesium Sulphate was $(3.79 \pm 0.25)$ minutes Vs $(9.61 \pm 0.75)$ minutes with only $0.5 \%$ Bupivacaine and complete motor block with $0.5 \%$ Bupivacaine +Mgso4 was (2.9 \pm 0.23) minutes Vs (10.4 \pm $0.63)$ minutes with sole $0.5 \%$ Bupivacaine. The result of this study matches with the study by Huban Dayioglu et al where duration of analgesia for knee arthroscopy was prolonged with $6 \mathrm{mg}$ 0.5\% Bupivacaine $+10 \mu \mathrm{g}$ Fentanyl + 50 mg Magnesium Sulphate than with $0.5 \%$ Bupivacaine $+10 \mu \mathrm{g}$ Fentanyl $(359.8 \pm 90.7)$ min Vs (263.8 \pm 110.7 ) minutes. Whereas time to reach sensory block upto T10 level did not change much $(21.5 \pm 4.5)$ minutes Vs (22.9 \pm 5$)$ minutes and time for complete motor block on the operated side was also not much significant (25min Vs 21 minutes) ${ }^{14}$. This variation of sensory and motor block may be due to low dose of $0.5 \%$ Bupivacaine of $6 \mathrm{mg}$ only with 50 Magnesium Sulphate and 10 $\mathrm{\mu g}$ Fentanyl. In another study by Hamed Sanad and Colleagues effects of addition of Magnesium Sulphate, Midazolam or Ketamine to hyperbaric Bupivacaine for spinal anaesthesia in lower abdominal and lower extremity surgery was studied. Here $15 \mathrm{mg}$ hyperbaric Bupivacaine $+50 \mathrm{mg}$ Magnesium Sulphate resulted analgesia for $(412.5 \pm 35.9)$ min Vs $(110 \pm 22.1)$ min with sole $0.5 \%$ Bupivacaine. Maximum sensory spread upto T10 level required $(25 \pm 2.2) \mathrm{min}$ in $0.5 \%$ Bupivacaine group Vs $(22.2 \pm 4) \mathrm{min}$ for $0.5 \%$ Bupivacaine $+50 \mathrm{mg}$ mgso $4^{15}$. Our study has shown long duration of analgesia by addition of Magnesium Sulphate to $0.5 \%$ Bupivacaine. Magnesium Sulphate is a non-competitive antagonist to NMDA receptor which prevents central sensitization from peripheral nociceptive stimulus. It has a weak analgesic property which may be the reason why total duration of analgesia has been prolonged moderately. Recently in one study done in rats by Kosh Lim HR and colleagues Magnesium sulphate did not reduce post-operative analgesic requirement ${ }^{16}$. We could achieve dense motor block and fast sensory onset with combined $0.5 \%$ heavy Bupivacaine $20 \mathrm{mg}+100 \mathrm{mg}$ Magnesium Sulphate. May be this was because of high dose of $0.5 \%$ Bupivacaine + Magnesium Sulphate used for vaginal hysterectomy. Even with that high concentration there were very few complications. The major complications recorded were hemodynamic alterations, nausea vomiting, shivering, high spinal or total spinal, headaches during operative or in the postoperative period. None of the patients in Magnesium group had hypotension, bradycardia, vomiting and shivering where as $0.5 \%$ Bupivacaine group resulted hypotension in six patients, bradycardia in four, vomiting in three and shivering in seven patients. None of the patient from both the groups had high spinal or total spinal anesthesia where intubation and ventilation was needed. Only one patient in $0.5 \%$ Bupivacaine + Magnesium Sulphate group had headache postoperatively. Regarding safety of intrathecal Magnesium Sulphate there are positive results in studies done both in animals and humans. In one of the study done by Chanimov and friends $1.26 \mathrm{mg}$ bolus intrathecal Magnesium sulphate given to rats on alternative days over 30 days produced transient sensory, motor block without clinical andhistopathologicalcomplications ${ }^{17}$. Hauold and Meltzer showed that intrathecal Magnesium (1000 mg-2000 mg) produced spinal anaesthesia including profound sensory, motor block, transient sedation without neurological deficit. In another study done by Saeki H \& colleagues neurotoxicity was seen in rabbits by intrathecal Magnesium sulphate of $2 \mathrm{mg} / \mathrm{kg}$ and $3 \mathrm{mg} / \mathrm{kg}$ rather than $1 \mathrm{mg} / \mathrm{kg}$ or $0.3 \mathrm{mg} / \mathrm{kg}$ after one week where significant sensory dysfunction occurred in 2 rabbits and motor dysfunction in one receiving $3 \mathrm{mg} / \mathrm{kg}^{18}$. In our study $100 \mathrm{mg} \mathrm{MgSO}_{4}$ intrathecal use in women undergoing vaginal hysterectomy showed no neurological toxicity during one month follow up periods.

\section{CONCLUSION}

The present study showed that time of onset of sensory and motor block as well as duration of analgesia of $0.5 \%$ Bupivacaine was potentiated by intrathecal Magnesium sulphate without major side effects.

\section{REFERENCES}

1. Bharti N, Madan R, Mohanty PR, Kaul HL. Spinal Midazolam added to Bupivacaine improves the duration and quality of Spinal anaesthesia. Acta Anaesthesiol Scand. 2003; 47: 1101-5.

2. Grace D, Fee JPH. Anaesthesia and adverse effects after intrathecal pethidine $\mathrm{Hcl}$ for urological surgery. Anaesth Analg.1995; 50: 1036- 40.

3. Woolf CJ, Thompson SW. The induction and maintenance of central sensitization is dependent on NMDA receptor activation; implication for the treatement of post injury pain and hypersensitivity states. Pain.1991; 44: 293-9.

4. Woolf CJ, Chong MS. Preemptive analgesia: treating post-operative pain by preventing the establishment 
of central sensitization. AnaesthAnalg.1993; 77: 36279.

5. Fawcett WJ, Max EJ, Male DA. Magnesium; physiology \& pharmacology. BJA.1999; 83: 302-20.

6. Herroeder S, Marianne E, Schonherr B, Stefan G, Dehert, Markusw, Holmann.Magnesium essential for anaesthesiologists. Anaesthesioloy.2011; 114: 97193.

7. Haubold HA, Meltzer SJ. Spinal anaesthesia by magnesium sulphate.JAMA.1906; 46: 647-50.

8. Ozalevli $M$, Cetin $T \mathrm{O}$, Unlugenceh $\mathrm{S}$, Guler $\mathrm{T}$, Isik G. The effect of adding intrathecal Magnesium Sulphate to Bupivacaine Fentanyl anaesthesia. Acta Anaesthesiol Scand. 2005; 49: 1514-9.

9. Buvendran A, Mcarthy RJ, Kroin JS, Leong W, Perry P, TumanKJ. Intrathecal Magnesium prolongs Fentanyl anaesthesia. Analgesia.2002; 95: 661-6.

10. Arcoini R, Palmisani S, Santorsola C, Sauli V, Romano $\mathrm{S}$, Mercuri M, Mas ciangelo R. Combined intrathecal \& epidural Magnesium Sulphate supplementation of spinal anaesthesia to decrease post-operative analgesic requirement- $\mathrm{A}$ prospective randomized double blind study in patients undergoing major orthopaedic surgery.ActaAnaesthesiolScaned.2007; 51: 482- 9 .

11. Ishizaki K, Sasaki M, Karasawa S, Obata H, Nara T, Goto F. The effect of intrathecal Magnesium sulphate on nociception in rats acute pain models. Anaesthesia.1995; 54: 241-6.
12. Zahn P K, Breman T Z. Lack of effect of intrathecally administered NMDA receptor antagonists in rats model forpost operative pain.Anaesthesiology.1998; 88: 43-56.

13. George M, Samir M. Clinical anaesthesiology. $2^{\text {nd }}$ ed. McGraw-Hill companies,inc;USA:1999. 237p.

14. Huban D, Zehra N, Asena $S$, Mine $S$ and Kamil T. Effects of Adding Magnesium to Bupivacaine and Fentanyl for spinal anesthesia in knee arthroscopy. J Anaesth.2009; 23: 19-25.

15. Hamed S, Tarek A, Mohamad H, Mohamad A. Effects of adding Magnesium, Midazolam or Ketamine to hyperbaric Bupivacaine for spinal anesthesia in lower abdominal and lower extremity surgery.Ain Shams journal of anaesthesiology. 2010 jan; 3: 43-52.

16. Kosh Lim HR, Kim DC, Han YJ, Choeh Song HS. Magnesium Sulphate does not reduce post-operative analgesic requirement.Aneasthesiology.2001; 95: 640-6.

17. Chanimov $M$, Cohen MI, Grinspun $Y$, Herbert $M$, Reif R, Kaufman I, et al. Neurotoxicity after spinal anesthesia induced by serial intrathecal injections of MagnesiumSulphate, An experimental study in a rat model.Anaesthesia.1997; 52: 223-8.

18. Saeki H, Matsumoto M, Kaneko S, Tsuruta S, Jun Cui Y, Ohtake K, et al. Is intrathecal Magnesium Sulphate safe and protective against Ischemic spinal cord injury in rabbits? Anaesth Analg. 2004: 1990: 180512. 